\title{
The Study of Barriers of Participative Management from the Perspective of School Administrators
}

\author{
Sana Safari \\ PhD in Higher Education Management ,Assistant professor, Department of Educational Sciences and Psychology, \\ Payamenoor University, Pobox 19395 -3697Theran, IR of Iran
}

\section{Amir Akbari Sarcheghaie}

MA in Educational Management, Department of Educational Sciences and Psychology, Payamenoor University, Pobox 19395 -3697Theran, IR of Iran

\section{Doi:10.5901/mjss.2016.v7n4s1p89}

\section{Abstract}

This study aimed to investigate the barriers to the development of participative management from the perspective of school administrators to identify inhibiting factors in Kermanshah. For this purpose, after the study of contemporary research findings, obstacles to the development of participatory management were divided in five groups of structural factors, human factors, and factors in information systems, and factors related to the nature and the workplace and for each of these components were determined. In order to assess the barriers to the development of participative management from the perspective of school administrators, a researcher-made questionnaire developed by Pournader (2013), Sadeghi Haddad (2012) and Negin Tagi (2005) was designed. The questionnaire was with 40 questions using a Likert scale. Its validity was confirmed through content validity and its reliability through Cornbrash's alpha $(89 / 0=\alpha)$. After determining the sample size using Morgan table by simple random sampling, questionnaires were distributed to managers. To analyze the data, SPSS and LISREL soft wares were employed. Results indicate that among the identified factors, the most important and influential hinder to the development of participative management from the perspective of administrators was related to human factors.

Keywords: Management, Collaborative management, Education

\section{Introduction}

In order to satisfy and fulfill their individual targets, people join an organization. They find the goals that one person cannot reach them alone, are realized through organizations and their participation. People need to cooperate with each other on all matters, and now in our country with regard to the advancement of management knowledge and the establishment of modern management in organizations and institutions, participation in management is of great interest [10]. Consultation, participation, and appreciation of teamwork resulted in aggregation of ideas and abilities and all things to the best, and if organizations want to achieve such results, they are inevitable to motivate and engage their employees and this is possible when people believe in the process, not the tools being influential factors in achieving the goals of the organization and they should value it and enjoy their work, take on their responsibility and try to improve it [4]. Participation is a process in which the employees of an organization voluntarily interfere in the affairs and activities provided that they bear power and motivation for effective intervention and collaborative management style is one in which the employees of an organization intervene and participate in the decision-making process. Emphasized participatory management style is based on voluntary cooperation and participation of employees and using ideas, opinions and initiatives of employees for solving problems of organization [5]. Partnership is key prerequisite for the development and expansion of an education. Education increases knowledge and ability of people and reinforces their desire for participation. Participation in management will help to reduce the amount of monitoring on staff and also increases efficiency of staffs and organizational effectiveness. In addition, they show their attachment to the objectives of the group and feel positive about themselves and help create a pleasant organizational climate [12]. Examination of barriers in the form of human factors revealed the role of human factors in the development of participative management and also the necessary attention to these factors, among other factors and variables and components classified as human factors to remove the obstacles for participative management development in training organizations. 


\section{Participation and Collaborative Management}

The most common way to solve the problem of disability in the organizations is optimal use of the potential of staff in using participatory management approach. A lot of reports indicate that the success of most corporates is due to their appropriate use of management style [8]. In literature, the concept of participation has numerous interpretations, some of which are as follows:

Bidirectional, useful and valuable link between two or more than two people Involvement of people in the economic, political, social and cultural processes influencing on the fate.

Mental and emotional involvement in the group situations that motivate them to achieve the goal of a group, to help each other and take their responsibility.

Actions that will increase the influence and responsibility of employees in the decision-making process through representation at different levels of the organization and facilitate the realization of democracy.

Organized ideas on how to manage a modern economy and a progressive institution.

Staff involvement in the formal or informal decision-making process of the organization [13].

Participative management, despite its long history was scientifically examined after the industrial revolution and its main purpose was the development of human values for all employees and use of their intelligence, talent and creativity for achievement of the company's goals.

Participative management has continued its development with help of thinkers such as Argyris, Likert, Herzberg and Lawler under different shapes and names such as MBO 8, proposals system, the quality improvement and the Authority groups [7].

\section{The Concept of Collaborative Management}

Participative management is to create a space and system where all employees and customers and contractors participate and collaborate in the management of an organization and process of decision-making, decisions and solving problems [7].

Lawler defines collaborative management as inviting all employees to strategic thinking and holding people responsible for doing something about the quality of corporate management [9].

The main emphasis of this type of management is on the voluntary cooperation of employees, customers and contractors and using their ideas, suggestions, technical ingenuity and ability to solve problems in the organization for continuous improvement activities [9].

\section{Prerequisites for Participation}

Organizations trying to implement participatory management, faced with a series of factors that have affected their management style. Herman (1990) points out that the development of participatory management that is possible to prevent its implementation depends on two factors.

The first refers to the organizational environment. The second refers to the internal factors that influence the participative management, including: the relationship between strategy, structure, culture and Sashkyn behavior refers to the growing number of internal factors that influence the participative management including values, attitudes, job design and organizational culture.

For successful participation in an organization, it is necessary to provide preliminary conditions for proper understanding and analysis and they believe in its profitability. Thus, providing cultural background and basis for the preparation of all those who are in the light of cooperative system is essential. Then, after that through cultural infrastructure, people were prepared mentally; it comes to the need for help of senior managers and high-level support of the system. Senior management support is one of the first requirements [12].

After the organization was prepared to promote the participation, then attention must be paid to the following tips:

1. Before the official start of the partnership, enough time should be provided for staff to become familiar with management procedure. Participation would not permissible in times of emergency and urgency.

2. Spiritual and material costs of participation should not be greater material and spiritual benefits.

3. The subject of participation should be relevant to participants so that they show their interest.

4. Participants should receive essential training to communicate and exchange ideas.

5. The partnership should create job loss among participants [12]. 


\section{Participatory Management Challenges}

Identification of challenges and obstacles of the participation system and harmful factors to the proper implementation of the system seems necessary to increase its advantages [1].

Through knowledge and experience, some numerous challenges are enumerated and recognized that can be classified as follows:

a) Cultural challenges

- Lack of sufficient justification for rejecting proposals

- Disbelief and management incentive [4]

b) Process challenge

- Focus of proposals on welfare issues, poor review of proposals received the lack of bonus payments [4].

- $\quad$ Lack of sufficient time and opportunity [1]

- Mismatch between features and the proposed system, the lack of real participation of the various units in the design of the proposal and its procedures [2].

c) Environmental challenges

- Organizational ineffectiveness of management and staff, lack of rights and benefits for most employees, lack of enough organizational authority [4].

- Bureaucratic and long hierarchical structure, uneven distribution of organizational authority [13]

- Disagreement between the objectives of the individual and organization, concentrated planned system [1].

\section{Research Methodology}

This research has an applied purpose and used descriptive survey for collecting information. In this study collecting data was carried out using survey methods.

To identify the obstacles for the development and partnership management and literature, a researcher -made questionnaire was designed using the Delphi method. It has 40 closed - questions on the Likert scale adapted from previous research and a number of questions was developed depending on personal characteristics of respondents.

The study population is consisted of 484 identified principals from all schools in Kermanshah. A sample of 210 principals was selected randomly using Morgan table to determine the sample volume. In order to check the validity of the content and face validity, the idea of professors and experts was used and reliability was obtained using the pilot questionnaire distributed among 40 school principals and the amount of its reliability using Cronbach's alpha coefficient was computed $a=0 / 89 \mathrm{ed}$. To extract data collected through questionnaires, descriptive statistics was used for the first part (tables, graphs, mean, and standard deviation) and inferential statistics and exploratory and confirmatory factor analysis and calculation of loadings each from the questionnaire in the form of software LISREL, SPSS were employed for the second part.

\section{Evaluation of Conceptual Model of Research}

To understand the underlying factors hindering the development of participative management in educational organizations, Delphi method was used. With this method, the values of some variables were excluded and the remaining cases were grouped at related factors. These results were used as input for further analysis. According to Delphi, the conceptual framework for the study took five questions tested with exploratory and confirmatory factor analysis.

The first question: are structural factors seen as hindering the development of participative management? Second question: Do human factors are considered as hindering the development of participative management? Third question: Is the planning system to be considered as a barrier to the development of participatory management? The fourth question: Does the collaborative management information system development is seen as an obstacle?

The fifth question: Is the factors related to nature and environments are considered as hindering the development of participative management? 
Figure 1: Conceptual model

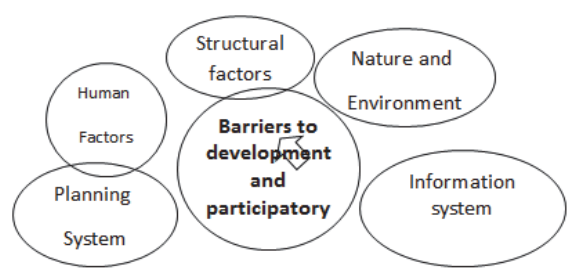

\section{Data Analysis}

Kolmogorov-Smirnov test for normality of variables was used to calculate the data. Results of the test are described below:

Table 1: Calculation of Kolmogorov-Smirnov test

\begin{tabular}{|l|c|c|c|}
\hline variable & statistics & number & significance \\
\hline Human Factors & 2.24 & 198 & $72.0 \%$ \\
\hline Structural factors & $1 / 25$ & 198 & $87.0 \%$ \\
\hline planning system Factors & $1 / 49$ & 204 & $94.0 \%$ \\
\hline management information system Factors & $1 / 76$ & 204 & $12 / 0$ \\
\hline nature and environment Factors & $1 / 35$ & 198 & $61.0 \%$ \\
\hline
\end{tabular}

According to Table 1, if significant level of Kolmogorov-Smirnov test displayed in the table is more than 05/0, it can be assumed that the data is normalized with high confidence. Otherwise it cannot be said that the data distribution is normal. According to the table above and a significant level values for the variables of human factors, structural factors, factors of planning, management information system elements, elements of nature and the environment it can be said that the probability distribution variables could well be normal.

Factors behind the test obstacles to the development of participatory management were extracted by main analysis and varimax rotation. In this version 5 operating factors were obtained according to the number of values higher than one (Table 2).

Table 2: Special value factors resulting from factor analysis without limiting factors

\begin{tabular}{|c|c|c|}
\hline explanatory power & equity & factors \\
\hline $20 / 2$ & $8 / 008$ & 1 \\
\hline $14 / 98$ & $5 / 99$ & 2 \\
\hline $5 / 92$ & $2 / 36$ & 3 \\
\hline $4 / 54$ & $1 / 82$ & 4 \\
\hline $3 / 80$ & $1 / 52$ & 5 \\
\hline
\end{tabular}

The results of the equity table (Table 2) show five factors. In the meantime, with 5 factors, questions of the questionnaire can be distinguished from each other so that the internal consistency of each subscale was also obtained. The results of this analysis are as follows.

Table 3: Percentage of explained variance for obstacles to participatory management, by any factor after varimax rotation barriers to the development of participative management

\begin{tabular}{|l|c|c|c|}
\hline Factors & equity & Percentage of explained variance & Percentage of varimax variance \\
\hline Human Factors & $5 / 17$ & $12 / 94$ & $12 / 94$ \\
\hline Structural factors & $4 / 19$ & $10 / 47$ & $23 / 94$ \\
\hline Planning System Factors & $2 / 91$ & $7 / 27$ & $30 / 69$ \\
\hline Management Information System Factor & $2 / 47$ & $6 / 17$ & $36 / 87$ \\
\hline Nature and Environment & $2 / 03$ & $5 / 08$ & $41 / 96$ \\
\hline
\end{tabular}


As shown in Table (3), the percent of explained variance by 5 factors is $96 / 41 \%$, which explain the first factor (human factors) with equity $17 / 5,94 / 12 \%$ the second factor (structural factors) with value especially $19 / 4,42 / 23 \%$ and the third factor (planning system factors) to equity $91 / 69$ / 30\%2, the fourth factor (MIS factors) with equity $2 / 472,36 / 87 \%$ and the fifth factor (nature and environment factors) with equity $2 / 03,41 / 96 \%$ from the total variance of the test.

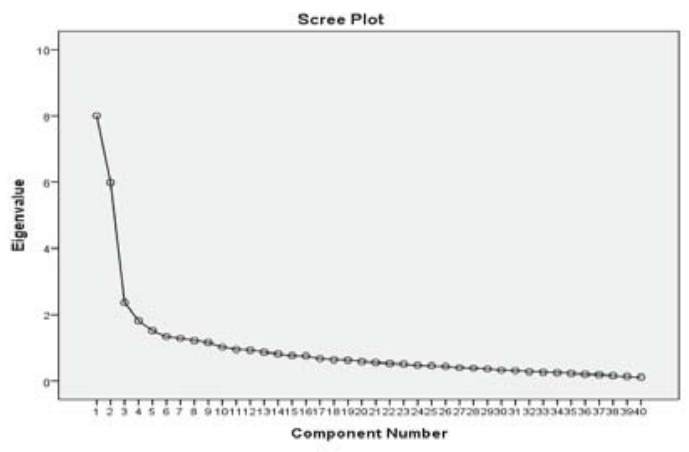

Chart: Justified Variance

By careful examination, it can be seen that amount of explained variance (eigenvalue) is reduced by extracting factors after the fifth factor.

Due to the support of the proposed model and the confirmation of validity and reliability, we can use test results to evaluate barriers to the development of participative management. The mean obstacles to the development of participatory management in the sub-components of human factors, structural factors, factors of planning, management information system factors, and workplace are presented in below table 4.

\begin{tabular}{|l|c|c|c|c|}
\hline Variable & mean & Standard deviation & Number of questions & number \\
\hline Human Factors & $37 / 51$ & $6 / 46$ & 12 & 198 \\
\hline Structural Factors & $29 / 90$ & $5 / 39$ & 10 & 198 \\
\hline Factors Of Planning & $14 / 38$ & $3 / 34$ & 5 & 204 \\
\hline Management Information System Factors & $17 / 41$ & $3 / 49$ & 5 & 204 \\
\hline Nature and Workplace Factors & $20 / 63$ & $4 / 98$ & 8 & 198 \\
\hline
\end{tabular}

Results Table 4 shows that among the mentioned factors, human factors are identified as the most important obstacles to the development and the most effective collaborative management of managers.

\section{Discussion and Conclusion}

Today the new participatory management style is one that, in addition to facilitating the achievement of organizational goals and individual can assist organizations in implementing strategic plans. The study aims to identify barriers to the development of collaborative management to prevent variables that were studied.

By reviewing the literature, the variables of barriers were identified and factors hindering the development of participatory management was developed based on a conceptual model. According to the conceptual model presented in this study, factors hindering the development of collaborative management are including structural factors, human factors, system planning, information systems, and the nature and environment.

Each of these dimensions were also included the following variables. Many of these variables were introduced in scattered research as hindering the development of participative management in educational organizations. By comparing model results with previous research that noted in the literature, it can be concluded that the pattern of results and the results are consistent with the findings of studies by Pournader (2013), Sadeghi Haddad (2012), Gahanian (2009), Nrgin Naji (2006).

So it can be concluded that the main obstacles to the development of participatory management in educational organizations include:

In the structural factors including rapid displacement and insecurity in the position of executive management, lack of appropriate determination of the duties and responsibilities of staff, bureaucratic and centralized, bureaucratic 
structure, weak regulations and procedures for employee participation, promote relationship between superior and subordinate employees and managers, the lack of variety in work activities, disagreement between the goals and objectives of staff and organization, the public schools and cumbersome regulations, permanent conflict managers to respond to letters and office circulars, lack of devolution to schools.

In terms of human factors, including the weakness of the managers (self-centered), the weakness of the assistants (selfishness), weak outreach managers, rather than individual interests over collective interests of the employees, lack of experience and collective life in society, the lack of mutual trust between individuals, organization, lack of staff confidence in their opinions, the lack of trust senior management to expand the participation in the school, lack of motivation to participate in the administration, the feeling of belonging to the organization's staff, lack of interaction, the exchange of information between management and employees, the lack of participation in performance evaluation.

In the planning system, including real-time decision making and cross in education, the high number of short-term needs and constraints in education, retardation of education in the planning for community issues, shortcomings of procedures and regulations on education, lack of training for staff on how to participate and benefit.

In the information system, including lack of staff knowledge and expertise, lack of access to adequate information staff, the lack of appropriate cultural backgrounds in education, political considerations (the need to keep some things confidential information), the lack of research in education.

The following factors related to the nature involves an imbalance of rights and benefits, work environment, unbalanced physical conditions, lack of safety at work, specialization of labor, lack of appropriate atmosphere to contribute intellectually and psychologically, lack of freedom to provide comments and suggestions related to labor, lack of independence in carrying out the work, policies and unfair policies and the lack of job justice.

\section{Reference}

[1] Boromand, N. (2002). Pathology of participatory management in organizations. Tadbir Publication (15).

[2] Anonymous. (2003). Suggestion System. Journal of Tadbir. 130.

[3] Pournader, A. (2012). Examine the barriers to the development of participative management from the perspective of management of education, Kalat Naderi (Khorasan). Master's thesis PNU of Tehran, Faculty of Literature and Humanities.

[4] Taddinie , Seyed D. (2008). Suggestion System involves important characteristic of administrative change from http://www.ido.ir.

[5] Galilee Khani, B. (2009). Suggestion System in collaborative management, Tehran Today Journal.

[6] Jahanian, R. (2009). The size and components of school-based management system and providing conceptual model, knowledge and research in Educational Sciences, seventeenth and eighteenth number: 74. 49.

[7] HosseinAlizadeh,A.(2005).ParticipatoryManagement.Fromhttp://www.moalemrc.com/Articles view

[8] Rezavi Amiri and S. (2006). Evaluation and development of proposals, Tadbir publication. Numb 172.

[9] Rahnavard, F and Saidie (2000). Explanation of Participative management philosophy. Tehran: Public Administration Training Centre.

[10] Salajegheh, Sanjar and studentHonaramooz , S. (2011). Suggestion System, a way to create a participative management, the third edition of the Journal of Educational Administration.

[11] Sadeghi Haddad, M. (2012). Review of barriers to the development of participative management in high school administrators and teachers. Master's thesis in Rajaee Teacher Training University, Faculty of Arts and Physical Education.

[12] Tossie , M. (2000). Management and employee involvement, Tehran: Administration Training Centre Publication

[13] Gharedaghi, B. (2008), An examination of management Negin Nagie , A. (2005). Examination of the barriers to the development of participative management school administrators and high school teachers, Masanie (Fars, province), Shahid Beheshti University, Faculty of Humanities. 